\title{
How are signals transduced across the cytoplasmic membrane? Transport proteins as transmitter of information
}

\author{
Larissa Tetsch $\cdot$ Kirsten Jung
}

Published online: 7 March 2009

(c) Springer-Verlag 2009

\section{Erratum to: Amino Acids}

DOI 10.1007/s00726-009-0235-x

In the published original version of this article, there is, unfortunately, a typing error in Fig. 3c.

The histidine kinase $\mathrm{CbrA}$ and the cognate response regulator $\mathrm{CbrB}$ were mistakenly written $\mathrm{CrbA}$ and $\mathrm{CrbB}$. The correct figure and capture are presented here:

The online version of the original article can be found under doi:10.1007/s00726-009-0235-x.

L. Tetsch $\cdot$ K. Jung $(\bowtie)$

Department of Biology I,

Center for Integrated Protein Science Munich (CiPSM),

Microbiology of the Ludwig-Maximilians-Universität München,

Großhaderner Straße 2-4, 82152 Planegg-Martinsried, Germany

e-mail: Kirsten.Jung@1rz.uni-muenchen.de 
A
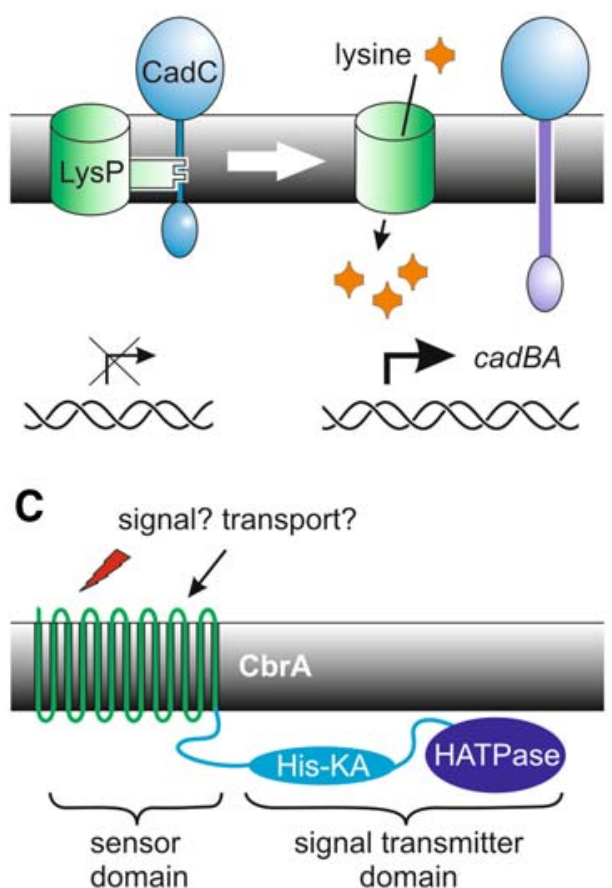

domain

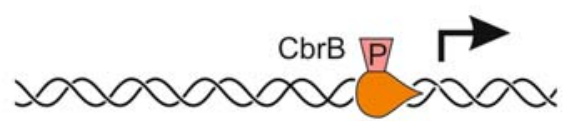

Fig. 3 Regulatory influence of transport proteins on membraneintegrated sensors. Secondary and primary transporters influence membrane-integrated sensors by direct interaction. a The lysine permease LysP inhibits the ToxR-like transcriptional regulator CadC in the absence of lysine via an interaction with the transmembrane domain of $\mathrm{CadC}$. This interaction prevents $\mathrm{CadC}$ from activating cadBA expression. In the presence of lysine, LysP transports lysine and the interaction between LysP and $\mathrm{CadC}$ is released. CadC becomes susceptible to activation by low $\mathrm{pH}$, the second stimulus needed for activation, and induces cadBA expression. b The $\mathrm{C}_{4}$-dicarboxylate uptake system DctA influences the two-component system DctB/DctD. In the presence of $\mathrm{C}_{4}$-dicarboxylates, DctB phosphorylates the response regulator DctD which induces gene expression. DctB functions as a sensor for dicarboxylates, but it is also regulated by DctA. When DctA is absent, DctB has a broader substrate spectrum, and it is also activated by other stresses such as

\section{B $\mathrm{C}_{4}$-dicarboxylates}

osmotic stress, other substrates
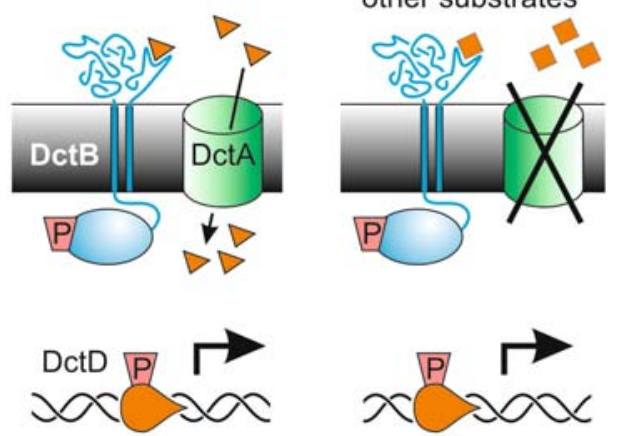

D

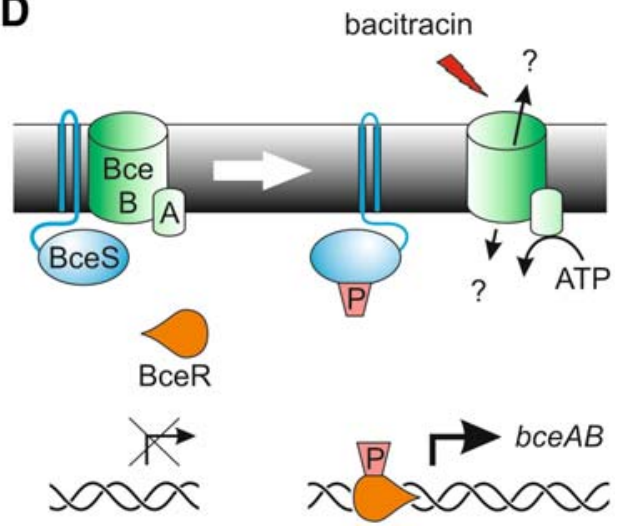

osmotic stress. Thus, DctA increases the specificity of DctB/DctD. c The CbrA/CbrB two-component system of various Pseudomonas species participates in the adjustment of the intracellular carbon/ nitrogen ratio of the cells, but the direct stimuli sensed are not yet identified. CbrA is composed of a sensor domain with high homology to $\mathrm{Na}^{+}$/solute symporters (SSS) which is covalently linked to the transmitter domain. It is still unclear whether the symporter domain mediates active transport or whether it is transformed into a pure sensing domain. $\mathbf{d}$ The bacitracin $\mathrm{ABC}$ transporter $\mathrm{Bce} \mathrm{AB}$ inhibits the histidine kinase $\mathrm{BceS}$ in the absence of bacitracin. In the presence of bacitracin the inhibitory effect is released, and BceS phosphorylates the response regulator BceR which in its phosphorylated state induces expression of the bceAB operon. The exact inhibitory mechanism is not elucidated yet, but transport of bacitracin is crucial for the activation of BceS. The direction of bacitracin transport by BceAB remains elusive so far 